Article

\title{
What the Framework Convention on Climate Change Teaches Us About Cooperation on Climate Change
}

\author{
David G. Victor ${ }^{1,2,3}$ \\ ${ }^{1}$ School of Global Policy and Strategy, University of California at San Diego, La Jolla, CA 92037, USA; \\ E-Mail: david.victor@ucsd.edu \\ ${ }^{2}$ Brookings Institution, Washington, DC 20036, USA \\ ${ }^{3}$ Global Agenda Council on Governance for Sustainability, World Economic Forum, New York, NY 10022, USA \\ * Corresponding author
}

Submitted: 22 April 2016 | Accepted: 20 May 2016 | Published: 8 September 2016

\begin{abstract}
Arild Underdal has been at the center of an important community of scholars studying global environmental governance. Since the 1990s that community, along with many other scholars globally, has offered important insights into the design and management of international institutions that can lead to more effective management of environmental problems. At the same time, diplomats have made multiple attempts to create institutions to manage the dangers of climate change. This essay looks at what has been learned by both communities-scholars and practitioners - as their efforts co-evolved. It appears that despite a wealth of possible insights into making cooperation effective very few of the lessons offered by scholars had much impact during the first two decades of climate change diplomacy. Indeed, basic concepts from cooperation theory and evidence from case studies - many developed in Arild's orbit-can explain why those two decades achieved very little real cooperation. The new Paris agreement may be changing all that and much better reflects insights from scholars about how to build effective international institutions. Success in the Paris process is far from assured and scholars can contribute a lot more with a more strategic view of when and how they have an impact.
\end{abstract}

\section{Keywords}

climate change; compliance; effectiveness; international cooperation; United Nations

Issue

This article is part of the issue "Climate Governance and the Paris Agreement", edited by Jon Hovi and Tora Skodvin (University of Oslo, Norway).

(C) 2016 by the author; licensee Cogitatio (Lisbon, Portugal). This article is licensed under a Creative Commons Attribution 4.0 International License (CC BY).

\section{Introduction}

From the early 1990s a large and growing community of scholars interested in the effectiveness of international cooperation has been orbiting around Arild Underdal. I consider myself one of the orbiters, dating from our joint work at the International Institute for Applied Systems Analysis (IIASA) and from many projects since.

Many other scholars have created their own orbits as well, and most of us have found ourselves circling many planets. But Arild's gravitational force has been intellectually strong for at least two reasons. One is that the Underdalian solar system has now been around and productive for a long time-perhaps longer than any other sustained research program on international environmental governance. Arild's planets have multiplied and colonized globally. The other is that Arild has held firm with a beautiful ascetic approach to theory. Whenever complex environmental issues are at stake it is easy to identify hundreds of variable and causal mechanisms that may be at work. But starting with Arild's work on fisheries (Underdal, 1980) where 
the core, important variables were the numbers of players in a negotiation and conflicts in their preferences-one of his intellectual gravitational forces has been a focus on what matters most.

In parallel with the emergence of a global research program on environmental governance the world's diplomats have also tried their hand at governance. What can be learned from the parallel efforts at scholarship and practice? Have the diplomats learned anything from the community of scholars who are studying systematically the business of diplomacy? Have the scholars learned anything from the diplomats?

In this essay-which is more of a thinkpiece than a tightly wound set of hypotheses tested with data-I aim to offer some answers to those questions. My focus is on the problem of global climate change-one that was just taking shape as a serious global problem around the same time that numerous research programs aimed at studying global governance were getting started in the early 1990s. Climate change is a good case for looking at whether theory and practice learn from each other because the problem itself has a deeply malign structureserious solutions require sustained cooperation over many decades with strong incentives to defect (Keohane $\&$ Victor, 2016). And precisely because of that malign structure, diplomatic efforts have been ongoing for many decades with, at best, mixed results.

I'll look at these questions from three perspectives. First, and briefly, what's gone wrong in the first two decades of multilateral cooperation? Second, what's new in the current efforts under the Paris accord-and why are these new efforts so promising after decades of gridlock and inaction? Third, what have we learned from all this for the study and practice of global environmental governance.

\section{What Went Wrong with Global Cooperation on Climate Change?}

A decade ago many of us in Arild's orbit took stock of what he had taught us. At that time, I wrote about the lessons learned from Arild's research for global climate change (Victor, 2006). At that time, my task was that of an intellectual coroner-probing why efforts to promote cooperation on climate change had, so far, achieved almost nothing. My assessment then still holds today, and it comes straight from work done in the Underdalian solar system.

Global efforts to address climate change were attempting to involve all nations on the planet in the crafting of universal agreements that would be legally binding. The inflexibility of binding law-backed by strict emission targets and timetables-was seen by many policy makers as a virtue because that would guarantee, they thought, that all nations' feet would be held to the fire. And the United Nations Framework Convention on Climate Change (UNFCCC) operated as a monopoly-it was the only forum for talking about multilateral actions on climate change.

It was not hard-from basic theory as well as the accumulated insights from research on the effectiveness of international environmental cooperation-to predict that this system would fail. Indeed, all the warning signs were found in the work of Underdal and his colleagues, among others. As I see it, the existing social scientific research on the effectiveness of international environmental agreements offered three warning signs to the architects of climate change diplomacy. And on all three of these warning signs the policymakers basically ignored everything we had to say.

First, a universal agreement amongst countries with wildly different preferences would be fantastically difficult to achieve. Indeed, success would be possible only by watering down the content to reflect the interests of the least ambitious actors (Underdal, 1980)-a strategy reflected in the UNFCCC itself. Or the participants could be narrowed to just a subset of supposedly more ambitious actors - as was done in the Kyoto Protocol-but that strategy would not work for the long term since most growth in emissions was from the other, excluded nations (Victor, 2001). Or, as in Copenhagen, gridlock would emerge.

A second warning sign concerned flexibility. An agreement that offered very little flexibility was also likely to yield the lowest common denominator or gridlock. As a practical matter, the question of flexibility arose most centrally around the policy decision of whether to make international agreements on climate change legally binding. Many of Arild's students who were engaged in the IIASA project in the 1990s were working on this question; my read of their research is an unambiguous endorsement for the merits of nonbinding agreements under special circumstances. I learned a lot, in particular, from research on the European acid rain regime which showed that binding commitments made countries wary about offering commitments that they weren't sure they could honor, but nonbinding commitments allowed them to offer "stretch" goals there were often very important (Wettestad, 1998). Research on the North Sea regime came to a similar conclusion, with the added insight that a regular set of high-level conferences backed by implementation review could turn those stretch goals into pragmatic action plans that governments would actually follow (Skjærseth, 1998). Implementation review helped keep governments accountable for their commitments and forced them to explain when they fell short-as often happened when governments adopted stretch goals. Across a wide array of other case studies, we saw similar patterns in our research, with a pretty clear trade-off between the legal status of an agreement and the possible impacts of that agreement on how countries managed very complex environmental problems (Victor, Raustiala, \& Skolnikoff, 1998). Since then, scholars working on 
similar topics have developed a more systematic set of insights around the relationship between hard law and soft law (Abbott \& Snidal, 2000).

The third warning sign was not so crisply developed in the 1990s when we were all working together at IIASA, although the elements of what has become a very interesting research program were beginning to take shape. Looking across many international environmental agreements, it is striking that some are highly integrated and centralized. The Montréal protocol on the ozone layer is a good example. Many others, however, are much more decentralized.

Working in the 1990s as part of the IIASA research project, I became interested in how governments were crafting international agreements on plant genetic resources. This is an area where governments and firms and NGOs all were trying to get things done, but nobody could agree on exactly the right course of action. Plant genetic resources were also intrinsically decentralized, as they implicate the international trade regime, many environmental regimes, and the industrial structure of important yet diverse industries. Decentralization in the legal regime helped these many diverse actors and institutions experiment with different ideas and figure out what works. The paper that came out about activity called these decentralized regulatory systems a "regime complex" (Raustiala \& Victor, 2004). Other people have applied other concepts to the same idea, notably Lin Ostrom's work on "polycentrism" (Ostrom, 2009). When I look back on that period I realize that we were grappling with the issues of decentralization and experimentation in many other areas of environmental regulation as well, such as whaling and protection of the oceans (Andresen, 1998; Stokke, 1998). Certainly I would not have been working on the idea of regime complexes if it had not been for the joint research with Arild in his solar system in the 1990s.

Certainly others will look back on the history of the first two decades of international diplomacy on the climate change issue and come to other conclusions. But when I look back on it what I see is a growing array of insights about how to make international cooperation on difficult topics such as more highly effective, and no relationship between those insights and what the diplomats were actually doing. What's different about the Paris approach is that it is much more reflective of some of the fundamental insights about bargaining, starting with the merits of allowing small groups to work on problems rather than just big universal agreements. That's an insight that I many others first learned from Arild.

\section{Why Was Paris Different ${ }^{1}$}

Why did Paris work when almost everything before it failed? Here I'd like to offer some answers to that

${ }^{1}$ See Victor (2015). This section draws largely from that piece. question and then explore how we academics who have been in Arild's orbit might help the Paris process become more effective.

My answer to the question of why Paris "worked" lies centrally with how commitments are being negotiated in the Paris process. Instead of setting commitments through centralized bargaining, the Paris approach lets countries set their own commitments. These "nationally determined contributions" are a starting point for deeper cooperation that will unfold over time. Once the Paris agreement enters into force and is fully in motion each nation will be expected to adopt a new pledge every 5 years in tandem with periodic overall efforts to take stock of how the group of nations is doing.

The flexibility of this pledge-and-review system helped transform climate diplomacy from the gridlock and impotence of the past. It makes it easier for national governments to tailor their commitments to what they know they can deliver at home. Frankly, most of the world's emissions come from countries that aren't centrally worried (yet) about global climate change. Take China, the world's biggest emitter. Its leaders have learned more about the dangers of unchecked climate warming, and that has made the country a bit more willing to act. But the nation still has other much more pressing priorities-like clearing the urban air of smog. Or India, another big emitter, which is also mainly focused on priorities other than global warming, such as making the nation's power grid more reliable.

The pledging approach lets these countries offer packages of policies that align with their self-interests while also doing something to slow the growth of global climate pollution. The same is true of most of the United States-outside the environmentally conscious coastal states, most of the nation is not centrally seized by fear of global climate change. When asked general questions by pollsters about climate change most Americans say they believe the science, but the best polling shows that people still aren't willing to spend much to combat this global problem (e.g., Ansolabehere \& Konisky, 2014). One of the reasons that past efforts to address this problem failed is that they were orchestrated around the idea that fixing global warming requires a treaty focused on strict limits on emissions of greenhouse gases. The new approach, by contrast, is organized around the idea that every country has its own national interests and needs the flexibility to align what it does globally with what is doable locally.

Eventually a much more integrated global treaty will be needed to make major cuts in greenhouse gas emissions-one directly focused on the global goals. But flexibility offers a way to get started and build confidence that, in time, will beget more confidence and a willingness to do more. This is the same theory-with a similar dose of flexibility-that guided the creation of the highly effective system for international coordina- 
tion of trade policy through the General Agreement on Tariffs and Trade (GATT), and since 1995 the World Trade Organization (WTO). Trade diplomacy began in the 1940s with simple, self-enforcing agreements that aligned with national interests; through successive rounds of bargaining those national policies were ratcheted forward and integrated. Easier problems were tackled first, building confidence that made it possible to tackle harder diplomatic challenges. The Paris agreement is intended to move the world in that direction.

There were many other sources of flexibility that also helped. Much of what was agreed in Paris, including notably the national pledges, is not strictly binding. Quite apart from whether the concept of binding international law is an oxymoron, the nonbinding status of commitments has been liberating for the reasons that academics already understood in the 1990s. There is a tradeoff between the rigor of the legal commitments and the level of ambition that countries are willing to offer, especially when governments are highly unsure about exactly what is feasible for them to implement at home

Another source of flexibility was the fact that many countries, long before Paris, were already working on the climate problem in smaller groups outside the United Nations. There were small groups of countries focused on forests - the area where the most progress in cutting emissions has been made in recent years. Other groups worked on the Arctic. Still others, with overlapping membership, are making tangible progress in cutting short-lived climate pollutants, such as soot and methane. There has been striking progress in regulating powerful heat trapping gases through the Montreal Protocol. Norway's role in all this is worth mentioning, in particular. There is no "small" country that has done more to advance cooperation on climate change than Norway.

All this flexibility didn't clear the political land mines of past efforts to cooperate on climate change. The least developed and most vulnerable countries in Paris were still rightly concerned that they get special treatment since they are bearing the brunt of climate impacts that they did not cause. The oil exporting countries, led by Saudi Arabia, still appear keen to make this agreement as ineffective as possible, since success could spell trouble for their lifeblood. These landmines sit armed and ready to explode at every large diplomatic meeting on climate change; flexibility makes it a bit easier to keep them from blowing up the whole process.

Division of the world into developed and developing countries-a concept enshrined in the 1992 Framework Convention on Climate Change and a regular feature of most modern global environmental agreements-cast a shadow over almost every discussion in Paris, since developing countries are determined to see developed nations bear most of the cost. But flexible pledges meant that nations from both sides of the divide could continue to hold their views about the right ways to categorize countries even though the categories are increasingly meaningless. The emergence of rapidly growing "middle-income" countriessuch as China, Brazil, and Korea-has changed the facts on the ground. The world has moved on, and the flexibility in the Paris process has made it easier for climate diplomacy to reflect those realities.

This shift from an integrated "top down" style of climate bargaining to a more flexible pledge and review system has its roots, in part, in academic thinkingincluding the work that began in Paris. However, there were many other handmaidens of success in Paris, especially the French hosts who made success a national priority. They adopted a strategy for success - one that revolved around flexibility rather than trying to shoehorn a lot of complex bargaining into a single, centralized binding agreement-but they also backed that strategy with massive diplomatic resources. They had a realistic sense of what was feasible along with a plan $B$ (and plans that ran deeper in the alphabet) in case things turned sour. They as diplomatic hosts were well integrated with the climate change secretariat, which also had a sober vision for what was feasible as a pragmatic strategy for obtaining that outcome. The contrast with the Danish hosts and the secretariat that managed the Copenhagen process could not have been starker.

Good hosting by the French helped to build good will-and focused minds on the harmful consequences of failure-and that was on display in many ways. A deal on climate finance-which in Copenhagen had been set at $\$ 100$ billion per year of new money by 2020 -could have easily blown up the talks, with both donors and recipients having strong incentives to hold out for the best deal. Good will and the costs to all sides from failure helped focus minds on an agreement that did little beyond what was already happening-with $\$ 100$ billion per year as the floor for new money. All the details that would make these commitments workable, such as accounting systems, were pushed into the future.

To be sure, some of the bargaining behaviors that have plagued international climate agreements in the past were still on display. One was revealed by the socalled "ambition coalition" - a big group of nations that pretended to seek the most ambitious agreement possible when, in fact, little held them together except slogans. This coalition favored strong language around the goal of stopping warming at well below 2 degrees Celsius above pre-industrial levels, ideally at 1.5 degrees. Looking at the feasibility of these goals was one of the tasks of the Intergovernmental Panel on Climate Change (IPCC) panel on which I served for the last five years. That experience convinced me that warming probably can't be stopped at those levels - the world has dithered for too long and must now brace for the consequences. Even a realistic crash program to cut emissions will blow through 2 degrees; 1.5 degrees is 
ridiculous. New goals are needed (Briggs, Kennel, \& Victor, 2015).

As academics, we need to avoid getting sucked into diplomatic debates that are, by design, fruitless. A flood of papers is being written about the Paris goals, and now that the IPCC has agreed to write a special report on 1.5 degrees even more papers will be written with the aim of being cited in that report. But the goals demanded by the "ambition coalition" have not been achievable for some time. Yet nobody within the official process has an incentive to state the truth about what is achievable because no single country is accountable for reaching these bold collective goals. Even in the IPCC, which should have been speaking truth to policy in its final Summary for Policy Makers, has no blunt statements about the impracticality of these goals (Edenhofer et al., 2014). That's because the IPCC's summary, like the Paris Agreement itself, is approved essentially by consensus-a method for making decisions that favors oblique language and a high ratio of bold pronouncements to practical realities. Yet the truth matters, because this agreement is now organized around goals that are not achievable, which will make the periodic stocktaking difficult to do with honesty. It will also make it harder for policy makers to put the needed focus on the huge needs for adaptation that are on the horizon.

On balance, all of this is encouraging news. A new process is under way, and it has many of the elements of success. What can we as academics do to help?

We in the academic community need to avoid getting drawn into debates that are structurally fruitless. But we should let ourselves play a bigger role in other aspects of the Paris process where hard-nosed social science of the Underdalian type is badly needed. Let me highlight two.

One is the question of how nations will actually know what each other is doing. Early in the planning process for the IIASA project we focused on this topicon what arms controllers called "verification"-as an area where more research was needed. Our advisors, such as Arild, guided us to research that would help explain the incentives for cooperation. And absent verification and eventually enforcement systems there were many kinds of malign problems for which cooperation would be impossible.

That logic now applies to climate change. Pledge and review is a long overdue way to get started with cooperation, but making that cooperation much deeper-with much costlier controls on emissions-will require the ability to assess whether each nation is doing its part and to link together the different national efforts into a more integrated, collaborative set of international agreements. Most of the details for how that will be done were deferred in Paris, and fleshing out a system for transparency is one reason why most observers think the "after Paris" process will be more important than the Paris meeting itself. Getting consensus on a serious review mechanism is all but impossible, which is why it will be important for some countries to volunteer themselves for careful review - to lead the way. A good model for this lies in the systems of ambitious commitments backed by implementation review that the IIASA team studied in the North Sea and other locales.

A robust review system would create much higher levels of transparency. That, in turn, could lower the transaction costs for more complicated and detailed integrated agreements. We in the social science community should develop some insights and predictions for exactly when and how those expectations will actually be realized.

Political scientists need to get more centrally involved in the debate about the role of markets in creating incentives to deepen international cooperation after Paris. Already many analysts are excited by what they see in Article 6 of the Paris agreement, which includes the provision for "internationally transferred mitigation outcomes," a clunky concept that surely will become known as ITMOs in the acronym riddled world of climate diplomacy. For many economists, ITMOs will be seen as an open door for international trading of emission credits-a concept that, in theory, could link national policy schemes into a more efficient, integrated global effort. From the first paper I wrote on this topic in the late 1980s I have been skeptical that international emission trading systems will work well because creating carbon credits is like creating a new form of money-a money that is only as good as the institutions that back it (Victor, 2009; Victor et al., 2014). Even in highly developed countries that is hard to do, a point that the Greek debt crisis has underscored for the Euro. Whether and how international trading will really work is an ongoing debate among analysts, and I expect that debate will now move into higher gear. This question of how different national regulatory and market systems will become interconnected over time-which will be essential to creating a more integrated approach to deep decarbonizaiton that eventually affects the whole world economy-is pivotal to the success of Paris. And it is an area where social science theory and empirical research have a lot to contribute.

Eventually, these efforts at building transparency will become a verification system-a topic that hasn't received much attention in most international environmental agreements where diplomats seem almost scared to talk about verification and enforcement, in contrast with arms control diplomacy where these topics usually occupy center stage (Ausubel \& Victor, 1992). Within the Paris process, where consensus is required, verification is a dirty word. Outside Paris, however, many countries, firms and NGOs are building the technologies-including satellite systems-that will be needed to make verification a reality. These facts on the ground will matter a lot more than the legal language in global agreements. Inside the Paris meeting 
halls the United States argued vehemently against strict monitoring and verification systems because it did not want the encumbrances of a global treaty. Up in space, however, the U.S. and other space leaders such as the European Space Agency are already testing the elements of a robust satellite monitoring system.

I don't see how robust new systems for review and verification will emerge from the global forum of the United Nations. More interesting, however, is the prospect for cooperation emerging in smaller groups"clubs." Once again, Arild colleagues are helping to show the way and steer other scholars to this important topic. Their work is aimed at trying to understand how different configurations of clubs can lead to deeper cooperation as well as the configurations that might get stuck with shallow cooperation (Hovi, Sprinz, Sælen, \& Underdal, 2016). A central issue will be the incentive structures and institutions for delivering penalties and rewards (Sælen, 2015).

The other area where the academic community could become more engaged with the after Paris process concerns the machinery of institutional design. Fundamentally, most of research on environmental cooperation in the Underdalian orbit has been institutional. It has been focused on how institutions can help decentralized parties realize collective interests. Looking to the future, this kind of research remains crucially important and will take us ever closer into collaboration with scholars in other disciplines, such as law.

For example, consider the topic of what international lawyers call "entry into force." Ambitious agreements usually don't enter into force automatically. Countries must sign and ratify them to signal that they, individually, will adhere. In addition, a big-enough group must join so that the agreement, as a whole, is triggered. In serious agreements, these triggers serve an important function: to prevent a nation that goes first with ratification from getting stuck inside an agreement when its competitors stay outside and gain advantages from free riding. In arms control diplomacy these provisions were the stuff of high politics, with extremely sophisticated entry-into-force provisions.

The entry-into-force trigger in Paris is anything but sophisticated. It simply requires ratification by 55 countries accounting for 55 percent of world emissions. Meeting those thresholds will be easyespecially the country trigger since there are already more than a 100 countries immediately eager and willing to sign and ratify. That threshold gives no small group the ability to block the agreement. Countries like Saudi Arabia and Russia, which are in the carbonexporting business, account for only one-tenth of world emissions, so they alone can't be spoilers. ${ }^{2}$ All

2 My calculations on the most recent set of 2012 emissions data from EDGAR, probably the most reliable source with global coverage of all warming pollutants. Also see Olivier, Janssens- the richest industrialized countries (about one-quarter of world emissions) won't be enough to bring the treaty into force. Even if those countries team up with the poorest countries, including the vulnerable low-lying island nations, they can't reliably cross the 55 percent threshold. And if just one big nation is flaky-say, the United States, where the fate of the agreement is hardly certain - then that group certainly falls short. ${ }^{3}$

Ultimately, the "middle-income" countries will be the king-makers. They, led by China (23 percent of global emissions), account in total for about 37 percent of world emissions. Even the U.S. and China, together, can neither block the Paris agreement nor assure its success. Countries must work together to bring this agreement into force or block it. This reality reflects the dispersion of power in the world system. That dispersion that is forcing nations to create new systems of governance that are more decentralized. It has also has removed the obvious leader (the United States) from its role as the planet's only leader. In Paris, leadership came not just from American diplomats but also billionaire philanthropists who pledged more patient capital support for new technologies and leaders of progressive cities and states. Perhaps the most pivotal nation in making Paris feasible was China: a nation that has now become much more willing to engage with global agreements if they are framed in China-friendly ways. Leadership came, as well, from smaller entrepreneurial countries-such as France that held the process together and Norway, which has done so much to fund new schemes to protect forests.

To me, the $55 \%$ emissions threshold reveals that the Paris agreement, for all the hoopla, is far from a serious scheme for deep international cooperation. It is a down payment on that system that is designed to come into force rapidly, and that's the best that can be hoped for right now. In future agreements one of the quickest ways to assess the depth of the effort maybe to look at the entry into force provisions - if they are sophisticated and difficult to satisfy then they will reveal a real concern by countries for creating an agreement that holds all its members accountable. Creating that kind of cooperation in a forum of nearly 200 countries will be hard, which is why most serious efforts are

Maenhour, Muntean and Peters (2015, p. 80).

3 Numerically, the entry-into-force provisions for the Kyoto Protocol were identical (55\%). However, there are two big differences that determined why the Kyoto system created stronger veto rights for a small group of countries. Kyoto's entry into force was calculated against a 1990 baseline when emissions were more highly concentrated around a few large countries-notably the U.S. and Soviet Union (Russia). And the Kyoto emission control (and entry-into-force) rules only applied to a core group of highly industrialized countries. Thus, de facto, two countries working together could block Kyoto: the U.S. and Russia. 
still likely to come from smaller groups-such as the US-China bilateral process announced in November 2014. We in the political science community along with scholars in international law should be working more on how these kinds of institutional designs intersect with countries' willingness to cooperate.

\section{What Is Being Learned?}

Looking back at the last 25 years of research and diplomacy related to global climate governance is sobering. For most of that time, the diplomatic efforts achieved very little. Moreover, the impact of systematic research about governance on the actual process of governance was tiny as well.

Paris may mark a turning point in which some of the ideas about how to create more effective governance-such as ideas about the benefits of working in small groups, about the utility of flexible legal instruments rather than just binding targets and timetables, and the ideas about how decentralized "polycentric" or "regime complex" systems function-are starting to have an impact.

I see at least three sets of insights into the learning process that might be relevant as we in the academic community plan our next phases of research.

First, at best, academics are just one set of actors in the broad contest to shape the choices about how to govern global problems. The history of climate change diplomacy suggests that our influence has been greatest when the system is in shock-as happened in the aftermath of the spectacular failure of the 2009 Copenhagen Conference. Had that conference been seen as a success then the evolution from the older, integrated and more top-down system of negotiating climate commitments might have been much slower. But failure animated a search for new ideas.

Put differently, Copenhagen opened a "window of opportunity" that allowed entrepreneurs to combine the problem of inadequate governance with the stream of "solutions" coming from political science and other social sciences (Kingdon, 2011). But this shock did not erase the role of basic politics. Powerful countries needed to favor new models-as happened when China, the US, France and many others favored a more flexible pledge and review system.

One implication of this first set of insights about "what is being learned" is that we must be patient. We in the academic community will develop dozens of ideas for improved governance. At best, only a few will be selected. Another implication is that the selection process is something we should learn more about. My view is that we have under-appreciated the role of knowledge brokers inside governments and international institutions-people who are trained in or well versed in the social science research yet have direct responsibilities for decisions (or at least how the prefer- ences of their countries are articulated) that relate to institutional design.

In this respect, there is an interesting disciplinary divide that may be muting our ability to have a greater impact. Most diplomats are lawyers. Yet despite an effort that is nearly thirty years old to promote communication between international law and the social sciences the track record of that communication is erratic. There are periodic review papers on what scholars have learned in one discipline that might be relevant to the other (e.g., Hafner-Burton, Victor, \& Lupu, 2012; Shaffer \& Ginsburg, 2012). But we aren't actually working well together, for the most part, and that probably has muted the impact of social science research on real world legal design.

Second, we should have a debate within our field about why we weren't more relevant during the first two decades of climate diplomacy. Back in the early 1990s there was no shortage of diverse ideas about how the climate problem might be governed. But the ideas adopted by diplomats were deeply rooted in one model: the Montreal Protocol. Is this choice simply the power of the idea of "Montreal" or were there other forces at work? There is a big literature on the role of ideas in foreign policy (Goldstein \& Keohane, 1993). Perhaps that literature can help us sort out the answers here.

My candidate for the leading answer is that the groups that were best organized and most committed to advancing the cause of climate protection - the major environmental NGOs (ENGOs) along with the European Union (EU)-were deeply committed to Montreal because it offered a clear example of a swift success. If so, this raises for us a big challenge in making the Paris model effective. There is a deep tension between the forces that are centrally motivated to address climate change and those that are willing to act on climate change if agreements are flexible and reflective on a broad array of other interests. The Underdalian insight in all of this-that is, the insight that is a bare bones reflection of the most important factor at work-is that the actors that are most highly motivated to make emission controls effective are a small and shrinking part of the global total while the countries whose own emissioncontrolling behavior matters most are all less motivated.

If this logic is right, then we need to learn how quickly the Paris process can be pushed without losing the support (and impact within) the countries that actually matter the most for solving the global problem. Ideally we would quantify that insight and share it with our colleagues in the climate modeling community so they can tell us more about the likely level of climate change that the real world will experience. I expect that likely real level of climate change will be a lot more than the aspirational goals set in Paris.

If this logic is right, then we also need to learn more about what is motivating the skeptical actors to control their emissions. Most of that answer lies in "co- 
benefits" that tend to accompany climate policy. For example, a big shift from coal to gas or other clean fuels lowers emissions of warming gases but can also help control local pollution.

Most social scientists working on this important problem want to find ways to help countries and ENGOs be more effective in pushing for deep global cuts in emissions. As part of that, we need to take a fresh look at how the rest of the world learns about what we do. Some of us have participated in the IPCC process, but that has been a clumsy way to get most insights from the social sciences into broader discussion because most of those insights are controversial and thus hard for the IPCC to synthesize.

A third insight about what's being learned concerns the right models for governance and expectations about rates of change. As noted above, I think the kind of model being developed here is similar to the "rounds" approach used in trade (Victor, 2011). Countries begin rounds with pledges and then stitch them together through lots of negotiations. That "rounds" process has become quite cumbersome as the membership of the GATT/WTO system has risen, which is a reminder that the basic "laws of numbers" about bargaining that Arild worked on decades ago still holds (Underdal, 1980). Big agreements are harder to reach than smaller ones-and the outcome will gravitate toward the least ambitious actor who is allowed in the room. Active tailoring of the "geometry" of the negotiations is needed.

We as a community should probably help diplomats understand the practical implications of different models. When viewed from a distance it will be clear that the Paris agreement was actually relatively easy to reach. Most of the work was done in the last 6 months-especially in the month or so prior to the conference and at many espresso-fueled meetings in the cloisters of the Paris conference center. Many of the disagreements in Paris were about processquestions such as the timing and frequency for stocktaking and fresh pledges, as well as language around the level of transparency and commitment-rather than substance, which was largely deflected through the pledge and review system. Most things that were hard to agree were set-aside for the future.

I have always found it amazing that environmental diplomats think they can get a lot done over short periods of time. When you look at other areas where cooperation is much deeper-like on economic matters and arms control-negotiation rounds run much longer and are more focused on substance. After Paris it will be very hard yet essential for diplomats to build the machinery that will make deeper cooperation possible in the future.

\section{Conclusion}

Over the last year there has been a lot written in antic- ipation and assessment of Paris. Most of it is highly positive-correctly pointing to the possibility that Paris has turned a corner. Gone, perhaps, are the days when diplomats attended endless COP and other intergovernmental meetings and make decisions that have little practical impact on the world.

The next few years are crucial in determining whether Paris was a flash in the pan or a real shift toward a more effective strategy. Too much attention has been focused on the agreement itself, a modest but useful 11-page document. More should concentrate on the 20-page detailed decision that was adopted alongside it and that outlines what countries should do once their diplomats get some sleep.

I am optimistic that Paris has turned the corner. That optimism is an unusual sentiment for me since, for twenty years, I have written a lot about why serious climate cooperation is hard to achieve and why most of what's been tried was bound to fail. Paris is different. That sobriety about what is possible has come from a few mentors, Arild notably among them, who have helped strip away all the complexity of international bargaining and focus on the core variables that explain most of the outcomes.

The good news in Paris is that diplomats, led by the French, have now done the same thing. Success in making that new vision a reality is far from assured. It must be earned. Confidence in the process is rising, but it can easily shatter.

For academics, there is a fresh opportunity to look closely at what the Paris process is trying to achieve and offer insights into how these new institutions can be designed and function. We were poised to do the same thing in the 1990s as the UNFCCC and then the Kyoto Protocol took shape, but the system was not interested in much advice then. Today is different.

\section{Acknowledgements}

Many thanks to Arild Underdal for many years of insights and discussions. Thanks to his colleagues, Jon Hovi and Tora Skodvin, for the invitation to participate in this volume and to the editorial team at Yale360 where I first explored some of these ideas related to what the social science community has actually learned in the UNFCCC process. And a big thanks to Steve Carlson for research assistance.

\section{Conflict of Interests}

The author declares no conflicts of interests.

\section{References}

Abbott, K. W., \& Snidal, D. (2000). Hard and soft law in international governance. International Organization, 54(3), 421-456. 
Andresen, S. (1998). The making and implementation of whaling policies: Does participation make a difference? In The implementation and effectiveness of international environmental commitments: Theory and practice. Cambridge, MA: MIT Press.

Ansolabehere, S., \& Konisky, D. (2014). Cheap and clean. Cambridge, MA: The MIT Press. Retrieved from https://mitpress.mit.edu/books/cheap-and-clean

Ausubel, J. H., \& Victor, D. G. (1992). Verification of international environmental agreements. Annual Review of Energy and the Environment, 17(1), 1-43. doi:10.1146/annurev.eg.17.110192.000245

Briggs, S., Kennel, C. F., \& Victor, D. G. (2015). Planetary vital signs. Nature Climate Change, 5(11), 969-970. doi:10.1038/nclimate2828

Edenhofer, O., Pichs-Madruga, R., Sokona, Y., Farahani, E., Kadner, S., Seyboth, K., . . . Minx, J. C. (2014). Climate change 2014: Mitigation of climate change. Contribution of Working Group III to the fifth assessment report of the intergovernmental panel on climate change. Cambridge, United Kingdom: Cambridge University Press.

Goldstein, J., \& Keohane, R. O. (Eds.). (1993). Ideas and foreign policy: Beliefs, institutions, and political change. Ithaca, NY: Cornell University Press.

Hafner-Burton, E. M., Victor, D. G., \& Lupu, Y. (2012). Political science research on international law: The state of the field. The American Journal of International Law, 106(1), 47-97.

Hovi, J., Sprinz, D. F., Sælen, H., \& Underdal, A. (2016). Climate change mitigation: A role for climate clubs? Palgrave Communications, 2, 16020. doi:10.1057/ palcomms.2016.20

Keohane, R. O., \& Victor D. G. (2016). Cooperation and discord in global climate policy. Forthcoming.

Kingdon, J. (2011). Agendas, alternatives, and public policies. Update edition (2nd ed.). Harlow, UK.: Longman.

Olivier, J., Janssens-Maenhour, G., Muntean, M., \& Peters, J. (2015). Trends in global CO2 emissions: 2015 Report. PBL Netherlands Environmental Assessment Agency. Retrieved from http://edgar.jrc.ec.europa. eu/news_docs/jrc-2015-trends-in-global-co2emissions-2015-report-98184.pdf

Ostrom, E. (2009). A polycentric approach for coping with climate change. Washington: The World Bank.
Sælen, H. (2015). Side-payments: An effective instrument for building climate clubs? International Environmental Agreements: Politics, Law and Economics.

Shaffer, G., \& Ginsburg, T. (2012). The empirical turn in international legal scholarship. The American Journal of International Law, 106(1), 1-46.

Skjærseth, J. B. (1998). The making and implementation of North Sea commitments: The politics of environmental participation. In D. Victor, K. Raustiala, \& E. B. Skolnikoff (Eds.), The implementation and effectiveness of international environmental commitments: Theory and practice. Cambridge, MA: MIT Press.

Stokke, O. (1998). Nuclear dumping in the Artic Seas: Russian implementation of the London Convention. In The implementation and effectiveness of international environmental commitments: Theory and practice. Cambridge, MA: MIT Press.

Underdal, A. (1980). The politics of international fisheries management: The case of the Northeast Atlantic. Oslo, Norway: Universitetsforl, Oslo.

Victor, D. G. (2001). The collapse of the Kyoto Protocol and the struggle to slow global warming. New York: Council on Foreign Relations.

Victor, D. G. (2006). Toward effective international cooperation on climate change: Numbers, interests and institutions. Global Environmental Politics, 6(3), 90103.

Victor, D. G. (2009). The problem with cap and trade. MIT Technology Review. Retrieved from https:// www.technologyreview.com/s/414025/the-problem -with-cap-and-trade

Victor, D. G. (2011). Global warming gridlock. Cambridge, UK: Cambridge University Press.

Victor, D. G. (2015). Why Paris worked: A different approach to climate diplomacy. Yale Environment 360.

Raustiala, K., \& Skolnikoff, E. B. (Eds.). (1998). The implementation and effectiveness of international environmental commitments: Theory and practice. Cambridge, MA: MIT Press.

Wettestad, J. (1998). Participation in NOx policy-making and implementation in The Netherlands, UK, and Norway: Different approaches but similar results? In Plinklet (pp. 381-429). Laxenburg and Cambridge: International Institute for Applied Systems Analysis and MIT Press.

\section{About the Author}

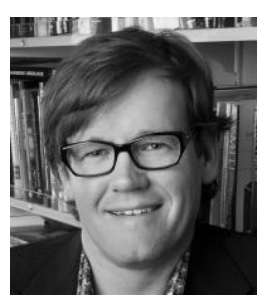

David G. Victor is Professor at the School of Global Policy and Strategy at the University of California at San Diego and Adjunct Senior Fellow at the Brookings Institution. He has worked on international cooperation related to environmental issues for nearly 30 years, most notably at project leader at the International Institute for Applied Systems Analysis in Laxenburg, Austria, in the 1990s. 